\title{
MIDAS
}

Museus e estudos interdisciplinares

$8 \mid 2017$

Dossier temático "Objetos e museus: biografias, narrativas e vínculos identitários"

\section{Entre a casa, o mar e a galeria. Os objetos animados de Salette Tavares}

Between the house, the sea and the gallery. The animated objects of Salette

Tavares

\section{Margarida Brito Alves}

\section{OpenEdition}

Journals

\section{Edição electrónica}

URL: https://journals.openedition.org/midas/1251

DOI: $10.4000 /$ midas. 1251

ISSN: 2182-9543

\section{Editora:}

Alice Semedo, Paulo Simões Rodrigues, Pedro Casaleiro, Raquel Henriques da Silva, Ana Carvalho

\section{Refêrencia eletrónica}

Margarida Brito Alves, «Entre a casa, o mar e a galeria. Os objetos animados de Salette Tavares»,

MIDAS [Online], 8| 2017, posto online no dia 31 juillet 2017, consultado no dia 28 juin 2022. URL:

http://journals.openedition.org/midas/1251 ; DOl: https://doi.org/10.4000/midas.1251

Este documento foi criado de forma automática no dia 29 setembro 2020.

\section{(1) 8 (2)

Midas is licensed under a Creative Commons Attribution-NonCommercial-ShareAlike 3.0 International License 


\title{
Entre a casa, o mar e a galeria. Os objetos animados de Salette Tavares
}

\author{
Between the house, the sea and the gallery. The animated objects of Salette
}

Tavares

Margarida Brito Alves

\section{NOTA DO EDITOR}

Artigo recebido a 19.03.2017

Aprovado para publicação a 28.06.2017

1 Um bule como sacrário, o lixo tornado jóia, uma peúga que é um cometa, uma toalha habitada por pratos, uma tesoura que também tem por função cantar e voar, uma cadeira que é uma escultura abstrata, uma garrafa vestida, uma agulha que é uma varinha de condão, uma gaveta que é um poema, nuvens carregadas de sonhos que se recolhem, dobram, engomam, guardam e empilham.

2 Em Lex Icon, um livro de poemas de Salette Tavares (1922-1994) inicialmente publicado em 1971, uma série de elementos que fazem parte de um contexto doméstico assume características outras. Sem que lhes seja retirada a sua dimensão funcional, no cumprimento das suas rotinas, muitos objetos de uso comum desenvolvem ações fantasiosas, tornando o quotidiano numa sucessão de acontecimentos de exceção. Nesses poemas surrealizantes, em que iminentemente tudo pode acontecer, não distinguimos quaisquer fronteiras entre o vivo e o inanimado, entre a realidade e o sonho, entre o possível e o impossível, ou até entre o pessoal e o universal.

3 Aqui, num ambiente doméstico em ebulição, o aparentemente banal adquire uma visibilidade que o transforma em extraordinário. Desterritorializados, os objetos ganham vida própria, deixando para trás as suas limitações materiais - e nunca são apenas o que parecem, revelando «o espaço fenomenológico da casa, os secretos complexos das 
relações humanas com as coisas, as estruturas dos objetos e dos gestos que as eles se ligam», tal como notou António Ramos Rosa (1972, 79). Este processo de deslocamento, em que qualquer elemento pode transcender o seu enquadramento convencional, abrindo-se a múltiplas leituras e possibilidades, é desde cedo identificável na produção de Salette Tavares.

\section{Ler e ver}

4 Com formação em Ciências Histórico-Filosóficas na Universidade de Lisboa, Salette Tavares começou por se salientar na poesia, tendo publicado, em 1957, o seu primeiro livro de poemas, Espelho Cego - no qual já se tornava evidente o seu interesse pela exploração do texto enquanto composição gráfica. Para serem lidos, mas também vistos, através de desalinhamentos, espaçamentos, intervalos e quebras, esses poemas adquiriam uma expressão visual que os ampliava enquanto significantes (Martinho 1995).

Dando sequência às suas pesquisas, será no âmbito das atividades do grupo da Poesia Experimental Portuguesa ${ }^{1}$ que, durante a década de 1960, Salette Tavares continuará a tomar a linguagem enquanto matéria de experimentação. Neste contexto, vale a pena salientar não apenas a sua colaboração nos Cadernos de Poesia Experimental ${ }^{2}$, mas também a sua participação na exposição coletiva Visopoemas, apresentada na Galeria Divulgação em 1965 - que incluiu o Concerto e Audição Pictórica, uma manifestação que é tida como o primeiro happening em Portugal (Hatherly 1995).

6 No mesmo período, Salette Tavares dará ainda sequência à publicação de poesia - tal como testemunham os volumes Concerto em Mi Maior para Clarinete e Bateria (1964), 14563 Letras de Pedro Sete (1965) e Quadrada (1967) -, mas paralelamente irá estender essa poesia a uma dimensão não só visual, mas também objetual e tridimensional, assumindo uma confluência entre produção literária e produção artística.

7 É justamente neste intervalo, ou nesta transmutação da palavra para a matéria, que podemos inscrever três da obras que realizou em 1963: Alquerubim, uma placa em alumínio anodizado com as dimensões de $100 \times 100 \mathrm{~cm}$, na qual gravou, repetidamente, a palavra que lhe dá título; Quel Air Clair, uma composição que tem por base uma moldura pintada de vermelho e que incorpora elementos encontrados no lixo (entre os quais uma lâmpada); ou ainda Maquinin (fig. 1), uma peça tridimensional, produzida em alumínio anodizado, que corresponde à tradução espacial de um poema que escrevera em 1959. ${ }^{3}$ 


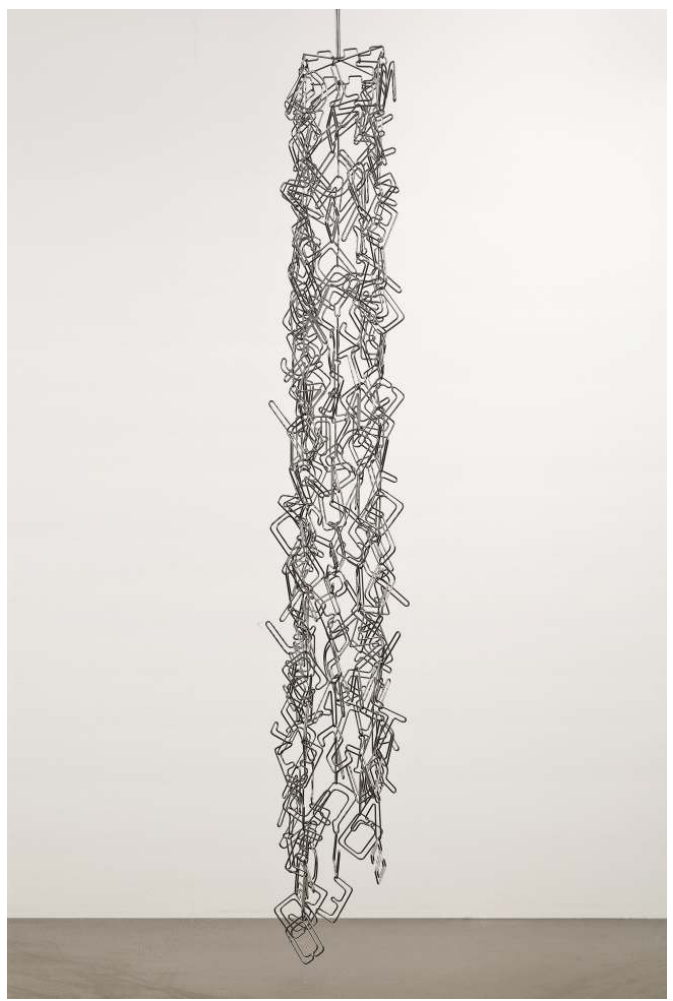

Fig. 1 - Salette Tavares, Maquinin, 1963, Museu Calouste Gulbenkian Fotografia de Paulo Costa

8 Não por acaso, fazendo migrar a palavra da escrita para diferentes suportes, é ao longo dos anos 1960 que Salette Tavares recorre a expressões como "poesia gráfica", "poesia experimental" ou "poesia espacial", para definir o seu trabalho. Nesse sentido, e partindo da escrita, o percurso que a sua obra descreve, poderá, de certo modo, ser perspetivado como um "processo de espacialização" (Alves e Rosas 2014,14), que transportará a poesia para uma dimensão escultórica ou até performativa - como se tornará mais evidente em propostas posteriores, nas quais procurará estabelecer uma relação direta, senão mesmo relacional, com o espectador.

Ao longo dessa trajetória, a presença do objeto será uma constante na sua produção, adquirindo uma crescente visibilidade. Contudo, a migração do texto para um quadrante tridimensional era já visível numa série de peças de cerâmica que produzira entre 1949 e 1963 - como exemplificam Peixe, Jarra Ferida, Sinhora do ó ou Jarra Pontos e Vírgulas, nas quais inscreveu versos, frases e sinais de pontuação.

Tal como a sua poesia, também estas peças são permeadas por uma dimensão quotidiana não apenas porque se trata de objetos que, na sua maioria, incorporam uma valência funcional, mas também porque, em alguns casos, funcionam como um suporte para o registo da sua própria vida pessoal, apagando assim os supostos limites entre o artístico e o não-artístico. É precisamente essa interferência do quotidiano familiar na produção de Salette Tavares que podemos identificar num prato pintado de preto (fig. 2), no qual, por entre manchas brancas e desenhos aparentemente infantis - que incluem um gato, um vaso de flores, um pássaro, uma carruagem ou uma menina com um guarda-chuva -, podemos reconhecer as palavras "Pepe", Mamã", "Bebe" ou "Mininha" - o nome que dava à sua primeira filha, Guilhermina. 


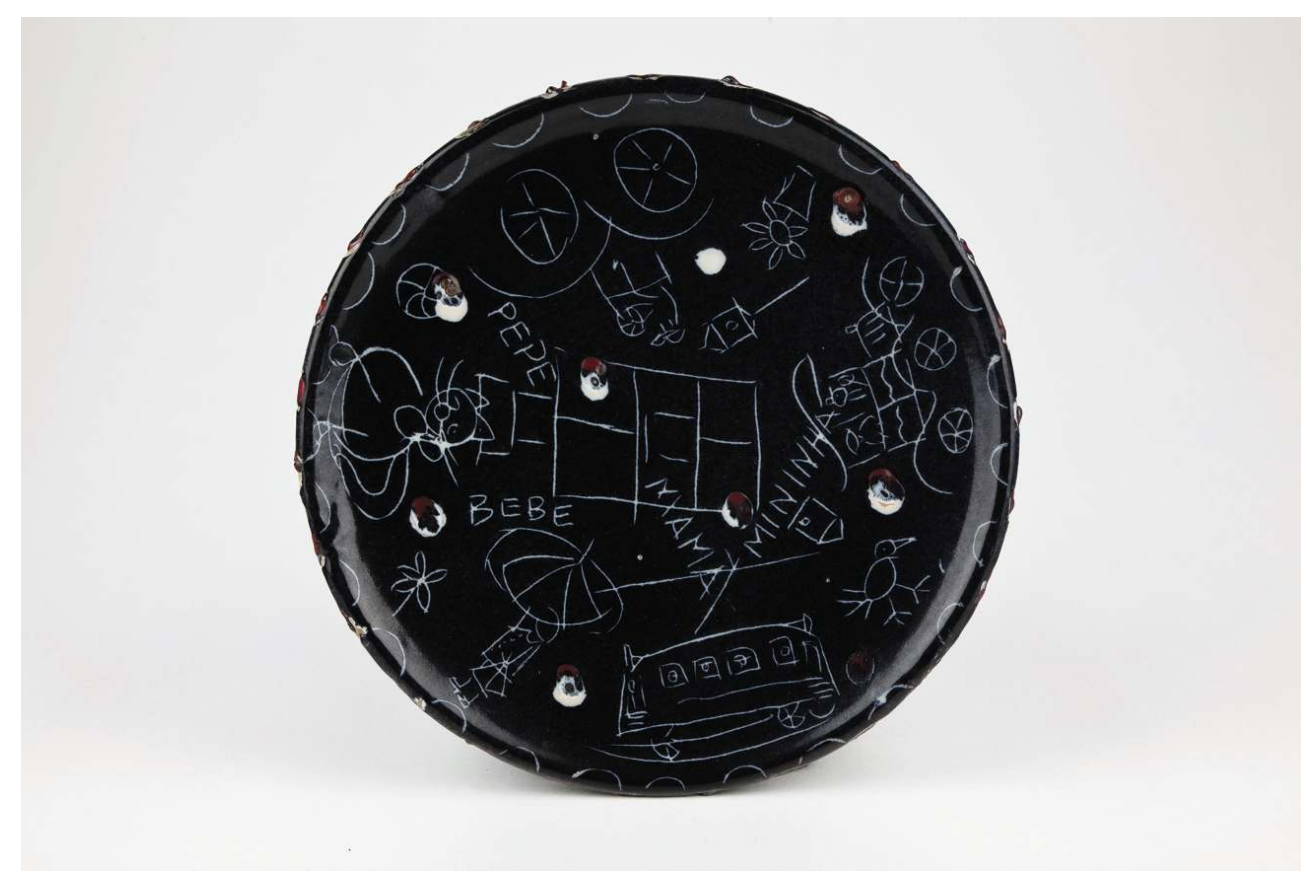

Fig. 2 - Salette Tavares, Prato, anos 1950, Museu Calouste Gulbenkian

Fotografia de Paulo Costa

\section{Oferecer e dialogar}

11 A relação com os filhos será um vetor que atravessará a obra de Salette Tavares, como confirmam os designados Diálogos Criativos, desenvolvidos entre 1959 e 1971, e inicialmente pensados como uma dialética para envolver os seus três filhos - Mininha, mas também Salettinha e Chico - numa dinâmica criativa desde crianças.

Assumidos como um jogo, estes Diálogos Criativos revelavam um sentido lúdico particularmente valorizado pela artista e equivaliam a um exercício de comunicação entre mãe e filhos que se formalizava através de objetos. Em substituição de palavras, essa comunicação expressava-se através de presentes que produziam em segredo e que, sucessivamente, trocavam entre si.

De um ponto de vista teórico, a noção de comunicação correspondia, de resto, a um dos interesses fundamentais de Salette Tavares - que, de forma inteiramente consistente, articulou a sua atividade no campo da teoria com a prática que desenvolveu enquanto artista. E, com efeito, reverberando a sua bagagem teórica, e em particular a Teoria da Informação de Abraham Moles (1958) - autor que numerosas vezes referiu nos seus ensaios $^{4}$-, os Diálogos Criativos que Salette Tavares mantinha com os filhos faziam corresponder uma prática familiar e lúdica, mas também artística, a um sistema determinado pela emissão, transmissão e receção. Perspetivando essa trocas de presentes, exatamente como comunicação, Salette Tavares viria aliás a referir-se a esse processo como «diálogos dos meus filhos comigo» (Tavares 1979, s/p.).

Efetivamente, tal como explicitou Marcel Mauss no seu célebre Ensaio sobre a Dádiva (1950)

- no qual estudou, enquanto fenómeno social, a prática de trocar presentes -, qualquer presente, embora voluntário e aparentemente livre e desinteressado, é parte de uma estrutura de reciprocidade que estabelece ligações entre doador e recetor, definindo-se 
como um perpétuo ciclo de trocas. Nestes termos, reforçando a sua dimensão comunicacional, também os Diálogos Criativos exigiam continuidade - cada presente funcionava como uma resposta, que, por sua vez, implicaria uma nova resposta.

Assim, de um crescente conjunto de objetos foram fazendo parte desenhos, fotografias e colagens, mas também composições feitas a partir de elementos aproveitados em casa ou respigados durante passeios em família pela natureza e, sobretudo, na praia - tais como pedaços de madeira, conchas, búzios ou arames enferrujados, que recolhiam junto ao mar (fig. 3).

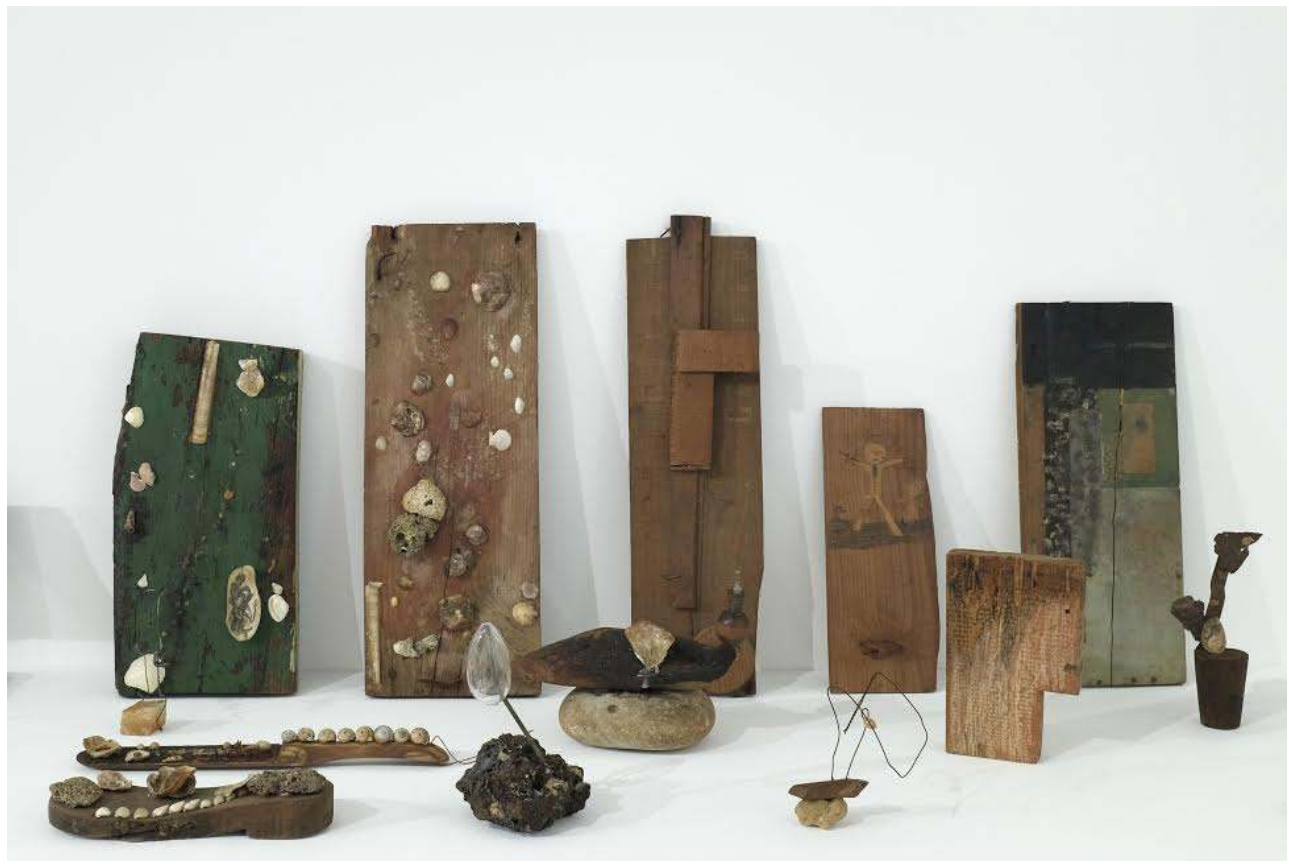

Fig. 3 - Salette Tavares, Diálogos Criativos, 1959-1971, Museu Calouste Gulbenkian

Fotografia de Paulo Costa

Enquanto memórias da relação entre mãe e filhos, esses objetos evocam diferentes experiências, vivências, ou até pequenos acontecimentos domésticos - tal como nos fazem adivinhar Tábuas e Roda do Carro das Bonecas (1959), Tábua, Concha, Arame e Ferro do Mar (1960), São José (1960) - constituído por uma maçaneta, uma moeda, uma rolha de uma garrafa de vinho e uma lâmina de barbear -; Tábua encontrada pelos três (1962), ou ainda Caderno do Chico feito com 6 anos para o meu Regresso dos EUA (1964) - executado com folhas de árvores dos parques de Filadélfia e de Chicago que Salette Tavares recolheu e enviou aos filhos durante uma viagem que fez aos Estados Unidos em 1964.

Como parte de um processo de «reciclagem do real», tal como escreveu Pierre Restany $(1990,76)$ a propósito do Nouveau Réalisme - que, nestes mesmos anos ${ }^{5}$, determinava o contexto artístico francês -, tratava-se de composições feitas a partir de desperdícios que, neste sistema, conquistavam uma nova vida.

Porém, ao mesmo tempo em que esses objetos eram formalizados como criações novas, ou renovadas, os elementos que incorporavam não deixavam de implicar outros tempos, outros lugares, outras histórias. Nesta perspetiva, funcionavam como vestígios que recuperavam um tempo passado, tornavam visível, e presente, algo que estava ausente desde logo a relação entre mãe e filhos que estava na sua origem. 
19 Até certo ponto, apesar da sua materialidade, esses objetos correspondiam a índices, que mantinham uma relação com um ato. Ambicionavam capturar e preservar o diálogo, associando assim, através da sua presença, um «extraordinário sentido de tempo passado», tal como notou Rosalind Krauss numa das suas reflexões sobre o índice (Krauss 1985, 217).

Os Diálogos Criativos não se limitavam contudo, à relação de Salette Tavares com os seus filhos. Alargando a esfera que definiam, neles participaram igualmente diversos amigos da família, contribuindo com objetos que, uma vez mais, testemunham uma relação íntima e quotidiana - como mostram o molde de um jarro executado em gesso oferecido por Ana Vieira, um Pano (1967) de Paula Rego, o Pacote de Rebuçados (1971) de Ana Hatherly ou a lata em alumínio Slogans's, de Emília Nadal.

21 Embora uma parte significativa destas contribuições fosse proveniente de artistas, o processo incluiu ainda a participação de outros autores relacionados com um meio cultural - como Sophia de Mello Breyner, Bruno Munari, Mário Barata, e Dulce d'Agro -, mas também de diferentes outros amigos, como Gertrudes, costureira, que ofereceu a desaparecida Conchas e Cesta (1971).

Ao materializarem laços de amizade, imateriais, esses objetos como que recriam uma rede de relações, um espaço social, ou um mapa afetivo e emocional, que transporta para uma dimensão artística um quotidiano partilhado. Nestes termos, o seu significado está para lá da sua dimensão material - a sua presença garante que as relações pessoais e sociais que os constituíram permaneçam num regime de visibilidade. Embora materialmente estáveis, trata-se assim de objetos animados - ou seja, dotados de vida.

Neste sentido, e recorrendo a Arjun Appadurai - que pensou nos modos como os significados atribuídos aos objetos resultam de motivações sociais e culturais -, podemos reconhecer que os significados destes objetos, «estão inscritos nas suas formas, mas também nos seus usos e nas suas trajectórias» - e "é apenas através da análise dessas trajetórias que podemos interpretar as transações humanas e os cálculos que animam as coisas» (Appadurai 1986, 5). Mais do que objetos, os Diálogos Criativos funcionam como extensões de relações de amizade, de interações entre pessoas próximas.

Com efeito, o processo criativo de Salette Tavares estava íntima e constantemente presente na sua própria vida pessoal e quotidiana, da mesma forma que essa dimensão pessoal era implicada na sua obra - como um jogo de espelhos.

No entanto, se em 1938, Johan Huizinga, definia o jogo como uma atividade voluntária «diferenciada da vida ordinária» (Huizinga 2014, 28), neste "jogo" de Salette Tavares podemos, pelo contrário, encontrar o esbatimento dos limites entre jogar e viver, ou entre criar e viver, ou ainda entre brincar e viver, uma vez que, como a artista chegou a referir, brincar seria um modo fundamental e privilegiado de atravessar a vida - um «estado natural e permanente» (Tavares 1979, s/p).

\section{Expor e partilhar}

Depois de, ao longo da década de 1970, Salette Tavares se ter dedicado sobretudo a um desempenho teórico e pedagógico ${ }^{6}$, foi em 1979 que teve a oportunidade de formalizar Brincar, uma exposição apresentada na Galeria Quadrum em Lisboa - um dos mais importantes espaços de apresentação e divulgação dos designados experimentalismos desse período, e que era então dirigido por Dulce d'Agro ${ }^{7}$. 
27 Assumindo, até certo ponto, os contornos de uma exposição retrospetiva, Brincar reuniu poesia experimental, trabalhos em cerâmica e em tapeçaria, assim como diferentes objetos, peças e estruturas tridimensionais - que evidenciavam a diversidade de técnicas e de suportes explorados por Salette Tavares desde o final da década de 1940.

De facto, a par de diversos novos trabalhos, foi nessa ocasião que foram expostas muitas das obras produzidas ao longo das décadas anteriores, entre as quais os Diálogos Criativos ou o que deles restava, tendo em conta a sua fragilidade. Aliás, no texto que escreveu para o catálogo da exposição, Salette Tavares refere-se como "restos" aos objetos que apresentou: «Quanto aos Diálogos Criativos cujos objetos tantas vezes me foram pedidos para exposições, embora eles sejam apenas restos porque muitos se foram perdendo, resolvi-me a expô-los [...]" (Tavares 1979, s/p).

No catálogo da exposição, as obras surgiam aliás divididas em duas secções: Diálogos Criativos e Poesia Espacial. Enquanto os Diálogos Criativos se subdividiam nos blocos Os Filhos e A Mãi e os Amigos dela, Respondem, a secção Poesia Espacial, independentemente da sua formalização, reunia todas as restantes obras apresentadas. No entanto, e apesar de Salette Tavares ter proposto esta distinção, um dos traços mais estimulantes da exposição era justamente a forma como todos os trabalhos expostos se articulavam e comunicavam entre si - mas também com o público.

Efetivamente, se os Diálogos Criativos, migrando de um quotidiano doméstico para uma galeria de arte, estabeleciam novos diálogos, convocando o espectador para a construção dos seus sentidos ao atribuir-lhes diferentes significados a partir das suas próprias memórias e referências pessoais, diversas outras obras encorajavam essa comunicação através de uma dimensão relacional, que implicava a participação ativa do público.

31 Certas obras, e sobretudo as que foram produzidas no ano da exposição, revelavam o empenho de Salette Tavares em explorar a noção de comunicação e em criar estruturas capazes de ativar o espectador através de uma experiência não apenas visual, mas fenomenológica - tal como acontecia com Bailia (fig. 4), uma instalação que transformava três estrofes de um poema ${ }^{8}$ numa estrutura em arame composta por três figuras de escala humana; Porta das Maravilhas, uma peça em acrílico transparente com um poema serigrafado, e que, tal como os seus poemas de Lex Icon, recuperava um elemento quotidiano; ou $O$ Rato Roeu, uma composição cujo título evoca um trava-línguas muito repetido por crianças, e que remetia para um espaço doméstico, consistindo numa mesa circular coberta por uma toalha em ráfia, na qual fora disposta uma combinação de rolhas e de estilhaços de vidro que formalizavam palavras. Tratava-se de trabalhos que desdobravam o próprio percurso da artista, ao oferecerem a possibilidade de serem lidos, vistos, mas também experienciados, uma vez que incitavam a que o espectador se deslocasse em seu redor, descobrindo a obra, mas igualmente o espaço da galeria através da obra. Estabeleciam um corpo-a-corpo entre a obra e o visitante - que, nestes moldes, era fisicamente ativado. 


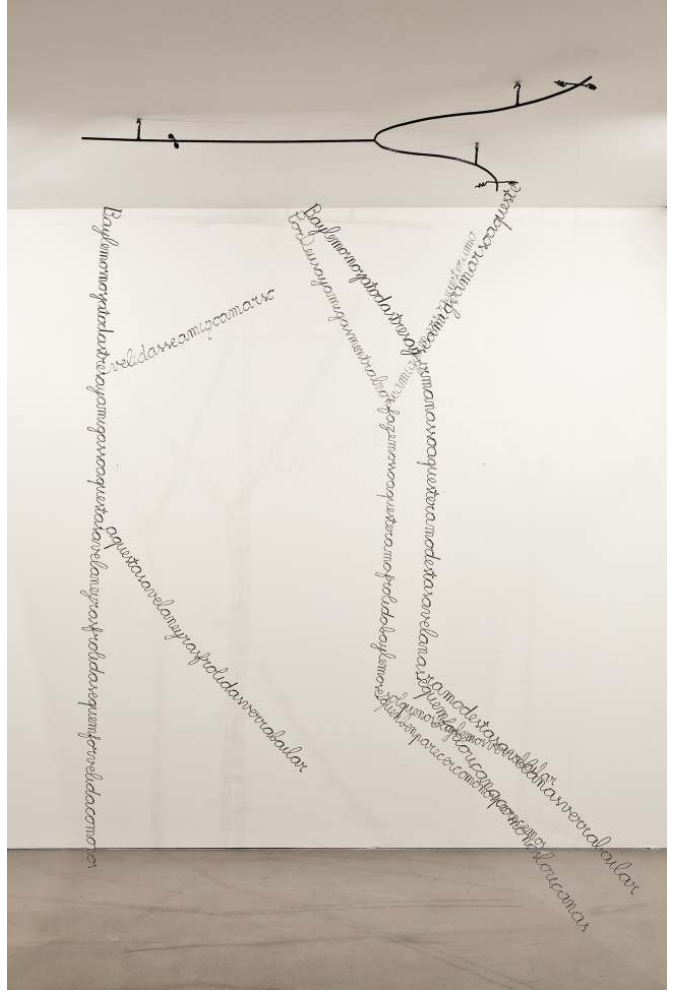

Fig. 4 - Salette Tavares, Bailia, 1979, Museu Calouste Gulbenkian Fotografia de Paulo Costa

Tendo em conta a sua articulação com uma esfera particularmente íntima e familiar, entre estas obras, destacava-se Dia Positivo (fig. 5), uma instalação que correspondia a uma mesa, na qual Salette Tavares posicionou quatro cartolinas com composições fotográficas que documentavam o crescimento dos seus filhos, e três estruturas em acrílico branco, 
que, como óculos, permitiam que os visitantes espreitassem um diapositivo referente ao dia (positivo) do nascimento de cada um deles.

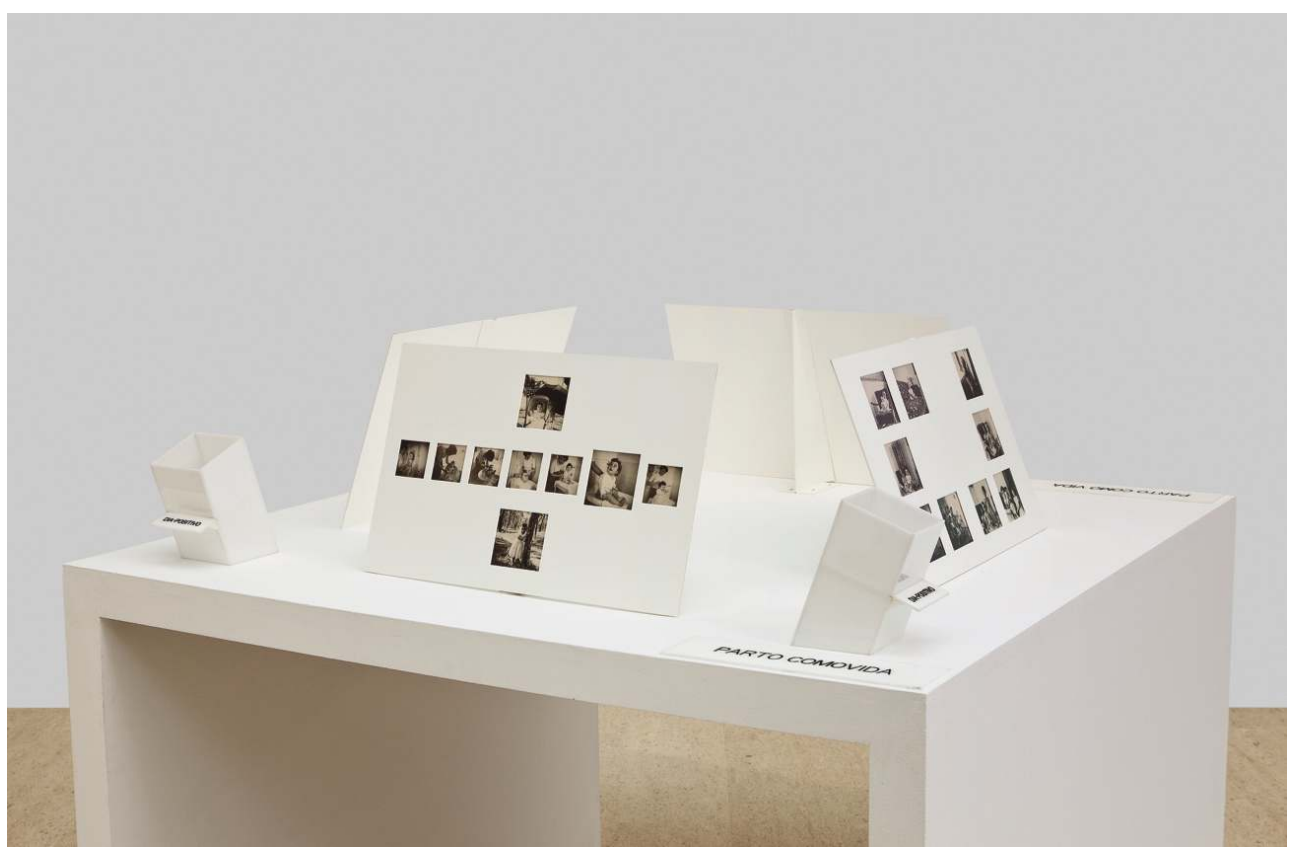

Fig. 5 - Salette Tavares, Dia Positivo, 1979, Museu Calouste Gulbenkian

Fotografia de Paulo Costa

Em Brincar, Salette Tavares partilhava deste modo o seu percurso enquanto artista, mas também uma trajetória pessoal, apresentada através de diferentes objetos que tanto testemunhavam diálogos passados como se afirmavam enquanto convites a outros, e novos, diálogos.

Com efeito, ao deslocar objetos, e em particular os Diálogos Criativos, diretamente relacionados com o seu quotidiano para dentro do espaço da galeria - um espaço outro, supostamente diferenciado de um quadrante vivencial embora com ele relacionado (Foucault 1994) - a artista desligava, até certo ponto, esses mesmos objetos da sua própria história e das suas afetividades. Passava a integrá-los dentro de um sistema expositivo regulado por códigos igualmente outros, que oferecia um «modo específico de visibilidade» (Rancière 2010, 89). Neste processo, apresentados sob uma nova perspetiva $\mathrm{e}$ abrindo-se a múltiplas interpretações, os objetos convertiam-se em peças insólitas, nas quais podiam, subjetivamente, ser depositados novos significados.

Contudo, se a passagem de uma esfera quotidiana para um enquadramento institucional correspondia a uma descontextualização, ou a uma (re)contextualização, Salette Tavares não assumia essa passagem como uma descontinuidade, procurando antes fazer conviver, ou até coincidir, ambas as dimensões. De facto, encarando a galeria como um espaço de permeabilidade, o modo como Salette Tavares inscreveu o seu quotidiano na exposição consistiu num exercício de negociação entre um antes e um depois - entre as circunstâncias da produção dos objetos e as condições de apresentação dos mesmos. Mantendo fluída a relação entre esses dois momentos através da partilha de elementos da sua vida privada - que, enquanto obras, tornavam indistintas as supostas fronteiras entre o artístico e o não-artístico -, mas também ao incitar os seus visitantes à interação, a artista testava convenções, abordando o espaço expositivo como um lugar de ensaio, de experimentação e de participação. 


\section{BIBLIOGRAFIA}

Alves, Margarida Brito, e Patrícia Rosas. 2014. “Uma Obra de Arte não é um Pastel de Massa Tenra.” In Salette Tavares. Poesia Espacial, 13-23. Lisboa: Centro de Arte Moderna-Fundação Calouste Gulbenkian.

Appadurai, Arjun. 1986. "Introduction: Commodities and the Politics of Value." In The Social Life of Things, 3-63. Cambridge: Cambridge University Press.

Foucault, Michel. 1994 (1984). “Des Espaces Autres.” In Dits et Écrits 1954-1988, vol. IV - 1980-1988, 752-762 Paris: Gallimard.

Hatherly, Ana. 1995. “Salette Tavares e a 'Poesia Experimental'.” In Salette Tavares. Poesia Gráfica, 11-15. Lisboa: Casa Fernando Pessoa.

Huizinga, Johan. 2014 (1938). Homo Ludens. A Study of the Play-Element in Culture. Mansfield: Martino Publishing.

Krauss, Rosalind. 1985. "Notes on the Index: Part 2." In The Originality of the Avant-Garde and Other Modernist Myths, 210-219. Cambridge: The MIT Press.

Marchand, Bruno. 2008. "Dulce d'Agro: Muito Provavelmente, a mais Bonita História Cultural de depois do 25 de Abril.” In L+Arte (jul.). http://arquivolarte.blogspot.pt/2008/06/dulce-dagro.html Martinho, Fernando J. B. 1995. "Nota sobre "Espelho Cego" de Salette Tavares." In Salette Tavares. Poesia Gráfica, 8-10. Lisboa: Casa Fernando Pessoa.

Mauss, Marcel. 2013 (1950). Ensaio sobre a Dádiva. Lisboa: Edições 70.

Moles, Abraham. 1958. Théorie de l'Information et Perception Esthétique. Paris: Flammarion.

Rancière, Jacques. 2010 (2008). O Espectador Emancipado. Lisboa: Orfeu Negro.

Restany, Pierre. 1990. 60/90: Trente Ans de Nouveau Réalisme. Paris. Édition de la Différence.

Rosa, António Ramos. 1972. “Lex Icon.” Colóquio/Letras 9: 79-80.

Tavares, Salette. 1967. “Teoria da Informação e Abraham A. Moles.” Brotéria LXXXIV (fev.): 152-173.

Tavares, Salette. 1979. Brincar (catálogo de exposição). Lisboa: Galeria Quadrum. 
Tavares, Salette. 1992. Salette Tavares. Obra Poética 1957-1971. Lisboa: Imprensa-Nacional/Casa da Moeda.

\section{NOTAS}

1. No quadro das atividades desse grupo, Salette Tavares colaborará com autores e artistas como António Aragão, Herberto Helder, António Barahona Fonseca, António Ramos Rosa, E. M. de Melo e Castro, Jorge Peixinho, Clotilde Rosa, Manuel Batista ou Mário Falcão.

2. Nos primeiros Cadernos de Poesia Experimental, de 1964, Salette Tavares publicou kinetofonias e diversos poemas em tipografia - tais como Efes e Aranhas, nos quais as palavras assumem uma forma visual. Intitulada Brin Cadeiras, esta colaboração teve continuidade em Brincade iras, publicada dois anos depois nos segundos Cadernos de Poesia Experimental, e que incluiu trabalhos como Al gar ismos, Alfinete, Alcantaril alfenim, ou Parlapatisse - poemas que assumiam uma experimentação gráfica.

3. Trata-se do poema Maquinin, que veio a ser publicado em 1967, no volume Quadrada.

4. Alguns dos ensaios da sua autoria foram publicados na revista Brotéria entre 1965 e 1969, sendo um deles especificamente dedicado a Abraham Moles (ver Tavares 1967).

5. A este propósito, não deixa de ser importante recordar que, com o apoio de uma bolsa da então recentemente criada Fundação Calouste Gulbenkian, entre 1959 e 1961, Salette Tavares trabalhou em França com Mikel Duffrenne e Etienne Souriau, e em Itália com Gillo Dorfles.

6. Entre outras atividades, Salette Tavares foi presidente da AICA - Associação Internacional de Críticos, entre 1974 e 1977; professora de Estética no Ar.Co - Centro de Arte e Comunicação Visual, entre 1974-75, e desenvolveu crítica de arte, tendo sido colaboradora das revistas Colóquio/Artes e Colóquio/Letras a partir de 1970 (e até 1989).

7. A este propósito, ver Marchand (2008).

8. Trata-se do poema Bailia das Avelaneiras, de Airas Nunes de Santiago, trovador galego do século XVIII.

\section{RESUMOS}

Partindo da articulação entre a atividade literária e a prática artística de Salette Tavares (1922-1994), e tendo em conta as múltiplas ligações que a sua obra estabelece com o quotidiano, este artigo centra-se na sua produção objetual, em particular nos designados Diálogos Criativos um conjunto de objetos, ainda muito pouco estudado, que foi desenvolvido entre 1959 e 1971. Estes objetos assumem uma dimensão lúdica e quotidiana, correspondendo a um processo de comunicação entre a artista e algumas das pessoas que lhe eram mais próximas. Nesse sentido, são analisadas as tensões que esses objetos estabelecem entre físico e imaterial, entre pessoal e relacional, ou mesmo entre arte e vida, para além de ser abordada a relação entre os Diálogos Criativos e diversas outras obras da artista. Com base na exposição retrospetiva de Salette Tavares: Brincar - organizada na Galeria Quadrum em 1979 -, é ainda problematizada a alteração operada nesses objetos através da sua deslocação de uma esfera quotidiana para um sistema expositivo. 
Drawing from the articulation between the literary activity and the artistic practice of Salette Tavares (1922-1994), and taking into consideration the multiple connections that her work establishes with everyday life, this article focuses on this artist's production of objects, in particular, the Creative Dialogues - a set of objects that has not yet been thoroughly studied, developed between 1959 and 1971. These objects take on a playful and everyday dimension, which corresponds to a process of communication between the artist and some of the people who were closest to her. In this sense, the tensions that these objects establish between physical and immaterial, between personal and relational, or between art and life, are analysed, as well as the relationship between the Creative Dialogues and several other works of the artist. Taking as a reference Salette Tavares' retrospective exhibition, Brincar - organized at the Quadrum Gallery in 1979 -, this article also problematizes the change operated in these objects by moving them from an everyday sphere to an exhibition system.

\section{ÍNDICE}

Palavras-chave: Salette Tavares, arte contemporânea, poesia experimental, poesia espacial, objetos do quotidiano

Keywords: Salette Tavares, contemporary art, experimental poetry, spatial poetry, ordinary objects

\section{AUTOR}

\section{MARGARIDA BRITO ALVES}

É professora auxiliar no Departamento de História da Arte da Faculdade de Ciências Sociais e Humanas da Universidade Nova de Lisboa, onde se doutorou em História da Arte Contemporânea em 2011. É vice-diretora e investigadora integrada do Instituto de História da Arte, sendo coordenadora do grupo de Estudos de Arte Contemporânea. É autora dos livros: A Revista Colóquio/ Artes (Colibri, 2007) e O Espaço na Criação Artística do Século XX: Heterogeneidade, Tridimensionalidade, Performatividade (Colibri, 2012). Foi co-curadora das exposições: Salette Tavares: Poesia Espacial (Centro de Arte Moderna/Fundação Calouste Gulbenkian, Lisboa, 2014) e Co-Habitar (Casa das Galeotas, Lisboa, 2016).

Instituto de História da Arte, Faculdade de Ciências Sociais e Humanidades da Universidade Nova de Lisboa, Av. de Berna, 26-C, 1069-061 Lisboa, Portugal, margaridabritoalves@gmail.com 